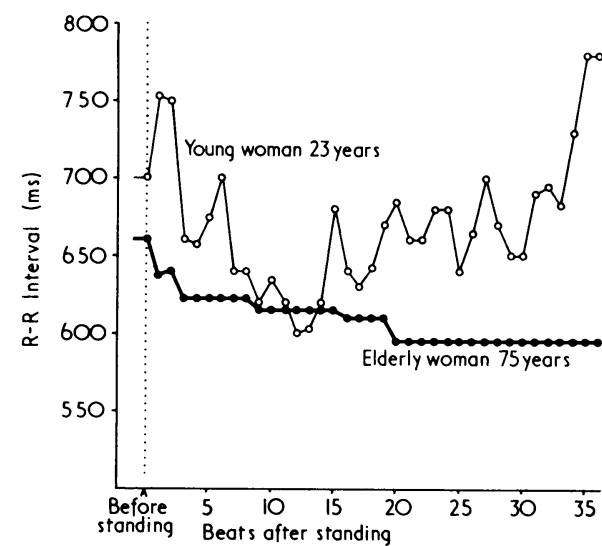

Heart rate response to standing in an elderly subject and a healthy young control.

response to standing was flattened. An example of such a flat response is shown in the figure and the pattern is similar to that found by Dr Ewing and his colleagues in diabetic patients with autonomic neuropathy. The $30: 15$ ratios in these elderly subjects were also low (mean 1.006, $\mathrm{SD} \pm 0.031$; young controls, mean $1 \cdot 107, \mathrm{SD} \pm 0 \cdot 161 ; 0.05<\mathrm{P}<0 \cdot 10)$ and there was no evidence of sinus arrhythmia in 10 of the 11 old people. These findings are in agreement with those of Drs W J MacLennan and A E S Ritch (25 February, p 505), but in the absence of serious disease in the 11 subjects it seems likely that the flattened response can be attributed to aging in the autonomic nervous system. Physiological impairment of autonomic function has been reported in a high proportion of elderly people by Collins et $a l^{1}$ in studies of thermoregulation in old age. ${ }^{1}$

University College Hospital

D J OLIVER Medical School,

London NW 1

'Collins, K J, et al, British Medical fournal, 1977, 1,

\section{Safety in laboratories}

SIR,-We consider, apropos your leading article on this subject (8 April, p 871), that while it is true that laboratory-acquired infections do not seem to be a serious hazard generally in pathology laboratories at present, it may be that with increasing work loads and increasing complexity of methods the situation may deteriorate unless codes of practice such as these mentioned in the article are produced for implementation where possible.

We take the point that processing of "all sputum and other material that may contain tubercle bacilli" in exhaust protective cabinets could cause problems in laboratories. Adequate exhaust cabinets such as are used in properly equipped laboratories should not produce the effect of concentrating an infective hazard. We think that codes of practice are produced to help and guide staff and those involved in laboratory management must be encouraged to employ such codes in a responsible way; in practice, application of these will need to be determined taking into account local circumstances.

Finally, in the last paragraph there is the naive implication that community physicians and environmental health officers are competent to inspect pathology laboratories. We have much pleasant and rewarding experience in collaborating with such staff and respect their expertise but have no doubt that unless they have appropriate laboratory training and experience (uncommon to our knowledge) they cannot be considered competent to inspect such laboratories. Indeed, this paragraph of the article could be quite disastrously counterproductive since, although inappropriate, it could be considered quite seriously by people in some fields of health care, who might in their ignorance attempt to act in error on this advice.

IAN A HARPER

Public Health Laboratory, New Cross Hospital

R G THOMPSON

\section{Antibiotic-associated colitis}

SIR,-Mr T T Irvin's comments (22 April, p 1051) on our paper on pseudomembranous colitis (18 March, p 675) are pertinent although not entirely practical.

We have certainly considered the possibility that the high incidence of pseudomembranous colitis is related to the large number of prophylactic antibiotics prescribed. Indeed, we think this is a major factor. In other surgical units in the same hospital, where prophylactic antibiotics are also used routinely, pseudomembranous colitis appears to be a rare event. It is only on our unit, where we undertake many clinical trials of antibiotic therapy, that pseudomembranous colitis has become so common. Naturally, therefore, we are fully aware of the possible role of multiple antibiotic administration. Nevertheless, we do not accept the statement that abdominal wound infection is rarely a life-threatening problem. In patients undergoing major colorectal surgery not protected by any form of antibiotic prophylaxis the incidence of intraabdominal infection is $10 \%$ and of septicaemia $12 \% 1$; both are life-threatening and lifeclaiming complications that can be prevented be appropriate prophylaxis. Surely it is not the time to put the clock back and abandon prophylaxis but to learn about the causes of complications of prophylactic antibiotic therapy and how to prevent them.

\section{J Alexander-Williams M R B KEIGHLEY}

General Hospital

Birmingham

Washington, J A, et al, Annals of Surgery, 1974, 180, 567.

\section{Management of severe acute asthma}

SIR,-Your leading article (8 April, p 873) on treatment of severe acute asthma does not mention the use of subcutaneous terbutaline. The subcutaneous route of administration is a useful acquisition to the list of present treatments.

There are occasions in general practice, and even in peripheral hospitals that are shortstaffed, when intravenous therapy is not convenient. In addition, older patients and those with associated cardiovascular problems may not tolerate intravenous infusions, with the added fluid load. The other large group of patients who would benefit from a subcutaneous injection are children, in whom it can often be extremely difficult to find a suitable vein

As the subcutaneous route of terbutaline has been shown to be effective ${ }^{1-4}$ I think it should be added to any list of asthmatic management.

J A Hughes

The General Hospital

Jersey, C1

Arner, B et al, Acta Medica Scandinavica, 1970 , Suppl 512, p 25. Suppl 512, p 25 .

Suppl 5 et al, Acta Medica Scandinavica, 1970 Holton, $\mathrm{K}$, British

Holton, K, British fournal of Diseases of the Chest,
$1974,68,111$.
Freedman, B J, British Medical fournal, 1971, 1, 633.

SIR,-I have delayed writing as I was sure that someone of greater authority would take up the cudgels for subcutaneous adrenaline, whose use you condemn in such a cavalier and unreferenced fashion in your leading article (8 April, p 873). One presumes that you are writing as a physician treating adults in hospital, and no doubt the main place for this drug is in children at home, though I would hold (and am supported by authorities such as Hutchison ${ }^{1}$ and Harris ${ }^{2}$ ) that it still remains an effective first-line drug for the hospital management of the young acute asthmatic. Its disadvantages, of poor absorption in the presence of peripheral collapse and cardiac stimulation, are widely known and its advantages, of reliability, safety, and ease of use in even a young child with inaccessible veins, are long tried and tested; the suggestion that alpha-receptors may be more stimulated by adrenaline than beta-receptors owing to betaadrenergic blockade: ${ }^{3}$ is unsubstantiated in practice. The only alternative subcutaneous bronchodilator, terbutaline, has never been compared with adrenaline and experience of its use is limited.

Sir, it ill becomes you to condemn longestablished drugs without even the benefit of argument.

TONY Waterston

Department of Child Health

wells Hospital,

Hutchison, J H, Practical Paediatric Problems, 4th edn. London, Lloyd-Luke, 1975.

${ }^{2}$ Harris, F, British Medical fournal, 1975, 4, 288.

\section{Contraceptive steroids and breast cancer}

SIR,-Mr J D Spencer and others, discussing this relationship (22 April, p 1024), report that the recurrence rate in 44 stage 2 breast cancer patients who had taken contraceptive steroids during the year before mastectomy was significantly lower than in a matched control series. Although the numbers and length of follow-up were limited, the observations suggest that the growth of recurrence may have been temporarily inhibited in some cases as a result of the patient taking a combined pill of progestin and oestrogen.

It is a pity that the authors failed to mention evidence of this, which was reported over 10 years ago. ${ }^{1}$ Soft-tissue manifestations of recurrent and advanced breast cancer in 42 women were treated with Lyndiol, an oral contraceptive containing a synthetic progestin of the 19-nor-steroid group associated with the oestrogen mestranol. After the contraceptive dose of one tablet daily for two months or longer almost complete regression of softtissue tumour was noted in 4 of 21 cases; with a dosage of 4-6 tablets daily it was noted in 5 of 21 other cases. The response rate and its mean duration were found to be almost identical with those noted in a series of 72 
similar cases treated by various progestins alone. $^{2}$

Inhibition of breast cancer growth by progestins is seen in both premenopausal and postmenopausal women but is favoured by the presence of circulating oestrogen. In the series treated with contraceptive steroids the response rate was only $6 \%$ in elderly patients with an atrophic vaginal smear, but it was $40 \%$ in younger patients with evidence of oestrogenisation in the smear. The observation is particularly interesting because Huggins ${ }^{3}$ reported that a combination of low-dosage oestradiol and high-dosage progesterone is capable of extinguishing the growth of the hormone-sensitive chemically induced mammary cancer in non-castrated female rats. He emphasised that the relative dose of oestrogen and progestin may be critical for success.

\section{Department of Oncology}

London SE1

Basil A Stoll

Stoll, B A, British Medical fournal, 1967, 1, 150.

2 Stoll, B A, British Medical fournal, 1967, 3, 338.

Huggins, C, Moon, R C, and Morii, S, Proceedings of
the National Academy of Sciences of the USA, 1967 , 48, 379.

\section{Antibodies to foodstuffs in schizophrenia}

SIR,-The "food allergy" theory of schizophrenia mentioned in your leading article (15 October 1977, p 976) holds that the primary lesion lies in the small bowel or liver, where a defective "gut barrier" permits undegraded dietary antigens to reach the circulation and there cause damage, either by direct toxicity or via hypersensitivity. ${ }^{12}$ We have therefore looked at schizophrenics' sera to see whether they contain antibodies to foodstuffs.

Sera were obtained from 41 patients attending mental hospitals in the Maidstone and Medway Health Districts. The principal diagnoses were: schizophrenia (31), "neurotic" (4), brain damage (3), and dementia (3). Control specimens were obtained from 57 unselected patients attending Manchester Royal Infirmary (leftover samples from the biochemistry laboratory). Sera were examined for antibodies against whole pasteurised cows milk (tanned cell technique ${ }^{3}$ ), wheat, barley, rice, soya bean, lentil, and haricot bean (indirect fluorescent antibody technique ${ }^{4}$ ). There was a highly significant association between mental illness and antibodies against one or more of the seeds tested, as shown in the table. Excluding the brain-damaged and demented patients from the "mentally ill" group increased the significance of the difference $\left(\chi^{2}=13.9\right)$. The commonest seed implicated was barley (13), followed by lentil (8), wheat (5), haricot bean (5), soya bean (3), and rice (1). There was no association between mental illness and antibody against cows' milk.

This preliminary study may be open to

Antibodies to seeds in sera from mental and control patients.

\begin{tabular}{l|c|c|c}
\hline & $\begin{array}{c}\text { Antibodies } \\
\text { present } \\
\text { to one } \\
\text { or more } \\
\text { seeds) }\end{array}$ & $\begin{array}{c}\text { Antibodies } \\
\text { absent }\end{array}$ & $\begin{array}{c}\text { Percentage } \\
\text { positive }\end{array}$ \\
\hline $\begin{array}{c}\text { Mental } \\
\text { patients (41) } \\
\begin{array}{c}\text { Control } \\
\text { patients (57) }\end{array}\end{array}$ & 22 & 19 & 54 \\
\hline
\end{tabular}

$x^{3}=12.61 ; P<0.0005$. objection on the grounds that the control patients were not well matched. Their average length of hospital stay was shorter than that of the psychiatric patients, they lived in a different geographical location, and their diet was likely to be different. Conversely, they may have included some who were mentally as well as physically ill.

Of course our findings do not prove the causal relationship of the food allergy theory, but the absence of this association would have been strong evidence against it. Further clinical studies are being prepared.

We thank the "Sanity" organisation for bringing us together and Dr Ifeonye for doing the venepunctures on the psychiatric patients. This study was inspired by the Schizophrenia Association of Great Britain.

\section{Department of Bacteriology} University of Manchester

IAN MASCORD DAVID FREED

\section{Maidstone and Medway Health Districts \\ Dohan, F C, et al, British fournal of Psychiatry, 1969 115, 595 \\ 2 Singh, M M, and Kay, S R, Science, 1976, 191, 401 1, Chin Yung, L, and Freed, D L J, Lancet, 1977, $1,1056$. 1977, 14, 85}

\section{Fetal abnormalities after abortion}

SIR,-It is to be hoped that Dr Alistair Gardiner and his colleagues (22 April, p 1016) will extend their study on spontaneous abortion and fetal abnormality in subsequent pregnancy to another index series following artificially induced abortions, which could provide a crucial test of their hypothesis that trophoblastic "rests" may be responsible for causing developmental abnormalities in the next child.

A spontaneous miscarriage must usually be a sign that all was not well with either the mother or the fetus, for otherwise why should it have occurred ? If so, there is likely to be an above-average chance that, for the same reasons, the next pregnancy will be similarly affected-which by itself could explain the observed increased incidence of fetal abnormalities, with no question of trophoblastic rests arising.

With artificially procured abortions, however, if the very few done for genuinely medical reasons are excluded, there is no reason to suppose that the prgenancies would have been otherwise than entirely normal. If the subsequent pregnancies showed the same higher incidence of fetal developmental abnormalities as in the spontaneous abortion series that would be consistent with the trophoblastic rest hypothesis, as would not be the case if the induced abortion series did not differ in this respect from the controls.

The authors do refer to two published studies involving induced rather than spontaneous abortions. The first ${ }^{1}$ is not really relevant since although a large series of abortions induced by dilatation and curettage showed a strikingly high incidence of infertility, and of miscarriages, stillbirths, and premature births in subsequent pregnancies, there was no mention of any specifically fetal abnormalities. But the second series, ${ }^{2}$ of 571 women with histories of previous induced abortions, mostly by suction techniques, and matched pair controls, showed no increase in fetal abnormality, nor indeed any other adverse effects on the subsequent pregnancy. It is true that the numbers were small (seven fetal defects after abortions and nine in the controls) and that developmental abnormalities were not distinguished from other fetal defects, and it is also true that a large majority of the previous abortions had been induced early in pregnancy (only 58 out of the 571 after the 12th week), when the effect of trophoblastic rests might be less important. But, so far as they go, these results would appear to be inconsistent with the trophoblastic rest hypothesis and, since it is a matter of some importance to arrive at a proper assessment of the risks of subsequent pregnancies involved in therapeutically induced abortions, this question ought to be pursued further, to an unequivocal conclusion.

C B GOODHART

Gonville and Caius College,

Cambridge

${ }^{1}$ Pantelakis, S N, Papadimitriou, G, and Doxiadis, S A, American fournal of Obstetrics and Gynecology,
$1973,116,799$. 2 Daling, J R, and Emanuel, I, New England fournal of
Medicine, 1977, 297, 1241.

\section{Maintenance treatment of duodenal ulcer with cimetidine}

SIR,-The results of long-term maintenance treatment of duodenal ulcer with cimetidine described by $\mathrm{Dr} \mathrm{E}$ Gudmand-Høyer and others (29 April, p 1095) are almost identical with those described by others using similar or different maintenance regimens with the drug. ${ }^{1}$ We would, however, like to comment on the statement of the authors that they designed their trial "to imitate the expected future use of cimetidine in clinical practice" and therefore employed radiological diagnosis on the basis of treatment. We will not comment now on the lack of validity of a clinical trial based on the presence or absence of radiological evidence of duodenal ulceration. However, we consider that treatment costing over $£ 200$ per annum per patient should not be given without a proper indication, and radiological deformity of the duodenal cap is not a proper reason and will not, we hope, become the basis of "expected future use" of cimetidine.

There is no reason, in the UK, why patients with suspected duodenal ulcers cannot have the benefit of having their diagnosis confirmed or disproved endoscopically.

\section{K G WORMSLEY} N R PEDEN

Ninewells Hospital,

Dundee

'Langman, M J S, and Wormsley, K G, Lancet, 1978, 1,932 .

\section{Serum ionised calcium concentration}

SIR,-Dr S C Conceicao and his colleagues (29 April, p 1103) demonstrate the discrepancy which may exist between the directly measured serum ionised calcium concentration and the value derived by correcting the total serum calcium for the serum albumin. Unfortunately they omit to provide the explanation for this phenomenon.

The serum calcium circulates in two main states. Approximately half is normally bound to albumin and is largely physiologically inactive. The remainder circulates in the free ionised state. The equilibrium between the two is determined not only by the serum 